\title{
The Wheat sprouts new life
}

\author{
Y. Joseph Woo, MD, and Amanda Edmonson, PA-C
}

\author{
From the Department of Cardiothoracic Surgery, Stanford University, Stanford, Calif. \\ Disclosures: Author has nothing to disclose with regard to commercial support. \\ Received for publication March 14, 2018; accepted for publication March 19, 2018; available ahead of print May \\ $10,2018$. \\ Address for reprints: Y. Joseph Woo, MD, Department of Cardiothoracic Surgery, Stanford University, Falk Build- \\ ing, 2nd Floor, 300 Pasteur Dr, Stanford, CA 94305. (E-mail: joswoo@stanford.edu). \\ J Thorac Cardiovasc Surg 2018;156:1-2 \\ $0022-5223 / \$ 36.00$ \\ Copyright (C) 2018 by The American Association for Thoracic Surgery \\ https://doi.org/10.1016/j.jtcvs.2018.03.054
}

The Toronto group of Hui and colleagues ${ }^{1}$ have published in this issue of The Journal of Thoracic and Cardiovascular Surgery an intriguing study of their institution's experience across two decades with more than 400 patients undergoing aortic valve replacement for both bicuspid and tricuspid valves and concomitant ascending aorta replacement, frequently along with replacement of the noncoronary sinus. Ostensibly, this is the contemporary Toronto experience with their version of the Wheat procedure, which in most modern interpretations varies from the original description. ${ }^{2}$ Likewise, there are variations of the Bentall procedure, the operation that in some centers ${ }^{3}$ might be the preferred approach for the cohort described by Hui and colleages. ${ }^{1}$

We all have anecdotes of patients who underwent aortic valve replacement with an ascending aortic replacement, most often at another institution, and then presented to us later with significant aortic root enlargement requiring reoperation (Figure 1). This type of patient has served as the fundamental rationale underpinning concomitant aortic root replacement in patients with bicuspid aortic valves undergoing aortic valve surgery for valid indications and varying degrees of aortopathy. We probably apply this logic to patients with diseased trileaflet aortic valves with moderately sized aneurysms.

To some extent, the ongoing debate of the embryologic versus biomechanical etiologic hypotheses behind bicuspid aortopathic aneurysm progression is under scrutiny here. A pure embryologic or genetic hypothesis would suggest that after aortic valve replacement, an individual's aortic tissue is still at risk for subsequent aneurysmal dilatation, whereas a pure biomechanical hypothesis would suggest that elimination of aberrant flow dynamics induced by stenosis or regurgitation would arrest further aneurysmal dilatation of native aorta. More than likely, multiple factors are involved, including variant aortic phenotypes.

This distinguished group, with extensive surgical expertise and robust medical data, followed a large cohort of individuals with normal to slightly enlarged aortic roots

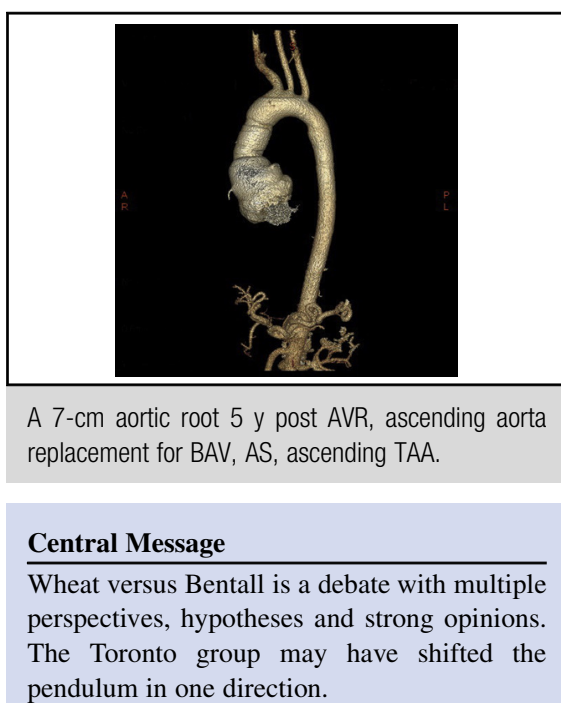

See Article page 5 .

$(<4.5 \mathrm{~cm})$ and found essentially no progressive dilatation of residual aortic roots through a long period. Although some patients underwent reoperation for prosthetic valve indications, incredibly, only one patient underwent reoperative aortic surgery for root aneurysm, 22 years after

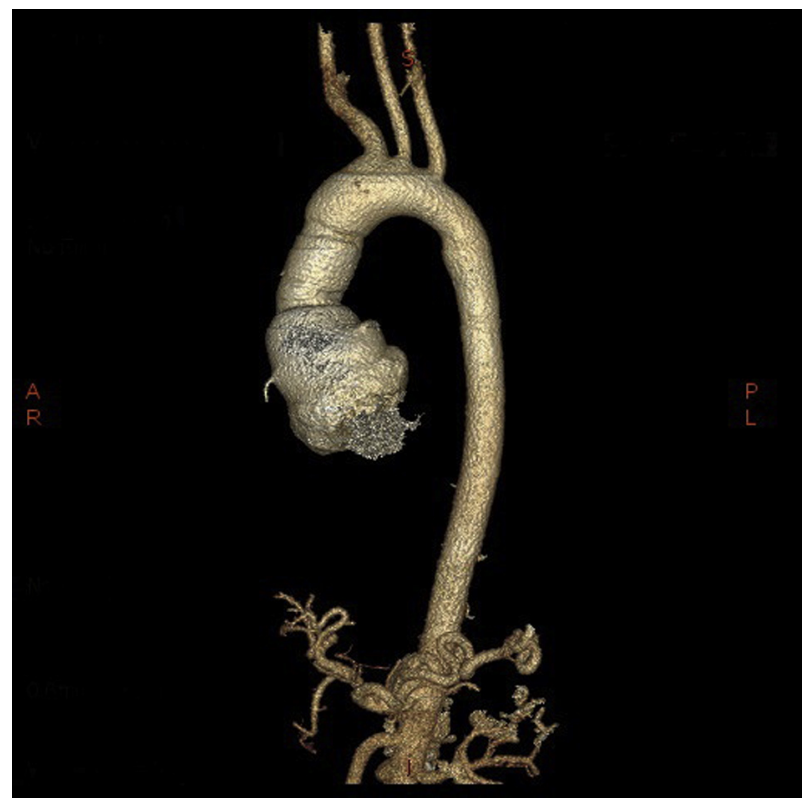

FIGURE 1. A 7-cm aortic root at 5 years after aortic valve replacement and ascending aorta replacement for bileaflet aortic valve stenosis, and ascending aortic aneurysm. 
the index operation. Clearly, during the described 20-year period at the University of Toronto, many patients underwent full aortic root replacement as their index operation. Although some may have been patients who would not have had dilation occur with time and thus did not need the root replacement, this is unprovable. Effectively, the Toronto surgeons have elucidated which patients should undergo Bentall procedures, or other types of full root replacement procedures, thus avoiding generating the anecdote represented by Figure 1. What was not included in this otherwise outstanding study is how the group specifically decided. In addition, another cohort unaddressed in this publication, but relevant to this discussion, comprises patients with aortic valve disease and moderate aortic dilation undergoing isolated aortic valve replacement who then either do or do not have dilation with time. Nevertheless, Hui and colleages ${ }^{1}$ are to be congratulated for developing some methodology, ranging perhaps from complex formulaic to pure instinctual, to identify patients who for a long time would do very well with a Wheat procedure. Perhaps this article will germinate new popularity and shift the paradigm with which concomitant aortic valve disease and aortic aneurysms are managed.

\section{References}

1. Hui SK, Fan CS, Christie S, Feindel CM, David TE, Ouzounian M, et al. The aortic root does not dilate over time after replacement of the aortic valve and ascending aorta in patients with bicuspid or tricuspid aortic valves. J Thorac Cardiovasc Surg. 2018;156:5-13.

2. Wheat MW Jr, Wilson JR, Bartley TD. Successful replacement of the entire ascending aorta and aortic valve. JAMA. 1964;188:717-9.

3. Maddalo S, Beller J, DeAnda AA. Bentall is not a Bentall is not a Bentall: the evolution of aortic root surgery. Aorta (Stamford). 2014;2:169-78. 